\title{
Anti-cancer effect of low dose of celecoxib may be associated with Inc-SCD-1:13 and Inc-PTMS-1:3 but not COX-2 in NCI-N87 cells
}

\author{
BIN SONG ${ }^{1}$, ZHEN-BO SHU ${ }^{1}$, JUAN DU $^{2}$, JI-CHEN REN $^{2}$ and YE FENG ${ }^{1}$ \\ ${ }^{1}$ Department of Gastrointestinal, Colorectal and Anal Surgery, China-Japan Union Hospital of Jilin University, \\ Changchun, Jilin 130033; ${ }^{2}$ Internal Medicine 2, The Tumor Hospital of Jilin, Changchun, Jilin 130012, P.R. China
}

Received September 6, 2015; Accepted February 23, 2017

DOI: $10.3892 / \mathrm{ol} .2017 .6316$

\begin{abstract}
In order to investigate the mechanism of celecoxib and whether long non-coding RNAs (lncRNAs) were involved in the effects of celecoxib treatment in NCI-N87 cells, NCI-N87 cells were treated with 15,30 and $60 \mu \mathrm{M}$ celecoxib and an MTT assay was performed to assess cell viability. Following treatment with $15 \mu \mathrm{M}$ celecoxib, the cell cycle and apoptosis were analyzed by flow cytometry, and the mRNA levels of lnc-SCD-1:13, lnc-PTMS-1:3, cyclooxygenase-2 (COX-2), integrin $\alpha 3$ (ITGA3) and DSH homolog 1 (DVL1) were detected by reverse transcription quantitative PCR (RT-qPCR) in NCI-N87 cells. MTT analysis demonstrated that celecoxib significantly inhibited cell viability in treated cells compared with untreated cells. Flow cytometry analysis revealed that, compared with untreated cells, the percentage of cells in the $G_{0} / G_{1}$ phase was significantly increased, and the percentage of cells in the $S$ and $\mathrm{G}_{2}$ phase was decreased. In addition, the percentage of early and late apoptotic cells was increased in cells treated with $15 \mu \mathrm{M}$ celecoxib compared with the control. RT-qPCR analysis also demonstrated that the mRNA levels of lnc-SCD-1:13, lnc-PTMS-1:3, ITGA3 and DVL1 were increased following treatment with celecoxib $(15 \mu \mathrm{M} ; \mathrm{P}<0.05)$. However, there were no significant differences in the expression of $C O X-2$ mRNA between cells treated with celecoxib $(15 \mu \mathrm{M})$ and untreated cells. The present study demonstrated that a low dose of celecoxib may be involved in regulating cell growth independent of COX-2 in NCI-N87 cells. Furthermore, ITGA3 and/or $D V L 1$ co-expressed with lnc-SCD-1:13 and lnc-PTMS-1:3 may be associated with the effects of treatment with a low dose of celecoxib in NCI-N87 cells.
\end{abstract}

\section{Introduction}

Gastric cancer (GC) is a common malignancy worldwide, characterized by high invasiveness and aggressiveness (1).

Correspondence to: Dr Ye Feng, Department of Gastrointestinal, Colorectal and Anal Surgery, China-Japan Union Hospital of Jilin University, 126 Xiantai Street, Changchun, Jilin 130033, P.R. China E-mail: bhc311@sina.com

Key words: celecoxib, anti-cancer effect, cyclooxygenase-2, long non-coding RNA
It is estimated that there are $\sim 990,000$ new cases of GC and that $\sim 738,000$ succumb from this type of cancer per year (2). Although a number of conventional therapeutic methods, including surgical excision and chemotherapy achieve satisfactory therapeutic effects for patients with early GC, a greater number of patients with GC at an advanced stage have poor prognosis (3). Therefore, despite increasing knowledge of the genetic and biochemical basis of GC, it is also essential to search for novel therapeutic targets and to develop more effective diagnostic and treatment methods.

A series of studies have reported that nonsteroidal anti-inflammatory drugs (NSAIDs) have an anti-cancer effect in various types of cancer, including breast cancer (4), esophageal cancer (5), colorectal cancer (6), prostate cancer (7) and GC (8). In addition to aspirin, celecoxib, a cyclooxygenase-2 (COX-2) inhibitor, has been demonstrated to be involved in uncontrolled cell proliferation, apoptosis, angiogenesis and metastasis $(9,10)$. Previous studies have suggested that celecoxib is able to induce cell apoptosis through the phosphoinositide 3 kinase/Akt signaling pathway (11) and to inhibit invasion through the adenine nucleotide translocator-dependent signaling pathway in GC cells (12). In addition, celecoxib has been reported to be able to prevent the development of GC in rats (13). Increasing evidence suggests that long non-coding RNAs (lncRNAs) are able to regulate tumor-suppressing or oncogenic effects, and lncRNAs may be considered as novel biomarkers and therapeutic targets for cancer $(14,15)$. However, an understanding of the function of IncRNAs in the treatment of GC with celecoxib remains limited.

A previous bioinformatics study has demonstrated that DVL1 and/or ITGA3, as well as their co-expressed lncRNAs, including lnc-SCD-1:13 and lnc-PTMS-1:3, were abnormally expressed in patients with GC following treatment with celecoxib. In the present study, the effects of a low dose of celecoxib on the viability, cell cycle and apoptosis of human GC NCI-N87 cells was investigated. In addition, the mRNA levels of lnc-SCD-1:13, lnc-PTMS-1:3, COX-2, ITGA3 and DVL1 were analyzed in order to investigate further whether IncRNAs are involved in the treatment of NCI-N87 cells with celecoxib.

\section{Materials and methods}

Cell culture. NCI-N87 cells were purchased from the Type Culture Collection of the Chinese Academy of Sciences 
(Shanghai, China). The cells were maintained in Dulbecco's modified Eagle medium (DMEM; Gibco; Thermo Fisher Scientific, Inc., Waltham, MA, USA) supplemented with 10\% fetal bovine serum (FBS; Gibco; Thermo Fisher Scientific, Inc.) in a $37^{\circ} \mathrm{C}$ incubator with a humidified atmosphere of $5 \%$ $\mathrm{CO}_{2}$ (Thermo Fisher Scientific, Inc.).

MTT assay. The cells $\left(5 \times 10^{3}\right)$ were seeded into each well of a 96-well plate and cultured in DMEM supplemented with $10 \%$ FBS. Following $24 \mathrm{~h}$ of culture at $37^{\circ} \mathrm{C}$ and $5 \% \mathrm{CO}_{2}$ with saturated humidity, the cells were treated with 0 (control group), 15, 30 and $60 \mu \mathrm{M}$ celecoxib (Sigma-Aldrich; Merck KGaA, Darmstadt, Germany), and subsequently incubated for $72 \mathrm{~h}\left(37^{\circ} \mathrm{C}, 5 \% \mathrm{CO}_{2}\right.$ with saturated humidity) (11). MTT (10 $\mu 1,5 \mathrm{mg} / \mathrm{ml}$; Shanghai Sangon Biotech Co., Ltd, Shanghai, China) was added to each well at the same time, and the cells were subsequently incubated for $4 \mathrm{~h}$ at $37^{\circ} \mathrm{C}$. Following the removal of the medium, dimethyl sulfoxide (DMSO; $100 \mu \mathrm{l}$; Shanghai Sangon Biotech Co., Ltd) was added into each well for $10 \mathrm{~min}$ to solubilize the formazan crystals at room temperature. The zero control (medium, MTT, DMSO) and blank control (no reagent) were set up. The absorbance was read at $570 \mathrm{~nm}$ using a microplate reader (BioTek Instruments, Inc., Winooski, VT, USA). All experiments were performed in triplicate.

Flow cytometry. The NCI-N87 cells were treated with a low dose of celecoxib $(15 \mu \mathrm{M})$ for $72 \mathrm{~h}$ at $37^{\circ} \mathrm{C}$. For cell cycle detection, the treated cells were collected by centrifugation $(250 \mathrm{x} \mathrm{g}$ for $6 \mathrm{~min}$ ) at $25^{\circ} \mathrm{C}$ and subsequently fixed with ice-cold $70 \%$ ethanol overnight. Next, the cells were centrifuged $(111 \mathrm{x} \mathrm{g}$ for $5 \mathrm{~min})$ at $25^{\circ} \mathrm{C}$ and re-suspended in $500 \mu \mathrm{l}$ phosphate buffered saline (PBS). The cells were subsequently treated with $50 \mu \mathrm{g} / \mathrm{ml}$ RNase A (Shanghai Sangon Biotech Co., Ltd.) for $30 \mathrm{~min}$ at $37^{\circ} \mathrm{C}$. Finally, the cells were stained with propidium iodide (PI; BD Pharmingen, San Diego, CA, USA) in the dark for $15 \mathrm{~min}$ at $4^{\circ} \mathrm{C}$ and detected using a FACSCalibur flow cytometer (BD Pharmingen). An annexin V-fluorescein isothiocyanate (FITC) apoptosis detection kit (BD Pharmingen) was used for the detection of apoptotic cells. The treated cells were digested with $0.25 \%$ trypsin-EDTA and collected by centrifugation at $250 \mathrm{x}$ g for $6 \mathrm{~min}$ at $25^{\circ} \mathrm{C}$. The cells were then washed once with PBS. Subsequently, the cells were resuspended with $1 \mathrm{X}$ binding buffer (from the annexin V-FITC apaoptosis detection kit) and stained with FITC-annexin V and PI in the dark for $15 \mathrm{~min}$ at $25^{\circ} \mathrm{C}$. Following this, $1 \mathrm{X}$ binding buffer $(400 \mu \mathrm{l})$ was added to the cells, and apoptosis was detected using a FACSCalibur flow cytometer (BD Pharmingen).

Reverse transcription quantitative polymerase chain reaction $(R T-q P C R)$. The cells were treated with a low dose of celecoxib $(15 \mu \mathrm{M})$ for $72 \mathrm{~h}$ at $37^{\circ} \mathrm{C}$. Total RNA was extracted using $1 \mathrm{ml}$ TRIzol reagent (Takara Biotechnology Co., Ltd., Dalian, China), and cDNA was obtained once using a reverse transcription kit (Takara Biotechnology Co., Ltd), according to the manufacturer's protocol. Primer sequences for ITGA3, DVL1, COX-2, lnc-SCD-1:13, lnc-PTMS-1:3 and glyceraldehyde-3-phosphate dehydrogenase are listed in Table I. SYBR Premix Ex Taq (Applied Biosystems; Thermo Fisher Scientific, Inc.) was used to perform qPCR. The thermocycler conditions
Table I. Primer sequences for real-time quantitative polymerase chain reaction.

\begin{tabular}{ll} 
Gene & \multicolumn{1}{c}{ Primer sequences (5'-3') } \\
\hline GAPDH-hf & GAAGGTGAAGGTCGGAGTC \\
GAPDH-hr & GAAGATGGTGATGGGATTTC \\
ITGA3-hf & GGACCTTACAACGCCGAGTG \\
ITGA3-hr & GGAGGCTCTTTGGCTTGTTTT \\
DVL1-hf & AGCACCTCATCCAGACTCATCC \\
DVL1-hr & GATGCTGATGCCCAGAAAGTGAT \\
COX-2-hf & CCCTGAGCATCTACGGTTTG \\
COX-2-hr & CAGTATTAGCCTGCTTGTCT \\
lnc-SCD-1:13-hf & AAGTCTTGAAGTTGGGTGTT \\
lnc-SCD-1:13-hr & GAAGATGGCAGAGCAGAAAG \\
lnc-LRR1-1:2-hf & GTGTCCGCACTAAGTTCGGCATCA \\
lnc-LRR1-1:2-hr & GTGTCCGCACTAAGTTCGGCATCA \\
lnc-PTMS-1:3-hf & ATCCCAAACGGCAGAAGACA \\
lnc-PTMS-1:3-hr & CAGAGCAGGGAGCCAGGTGA
\end{tabular}

GAPDH, glyceraldehyde-3-phosphate dehydrogenase; ITGA3, integrin subunit $\alpha 3$; DVL1, dishevelled segment polarity protein 1 ; COX-2, cyclooxygenase-2; lnc, long non-coding RNA; hf, forward; $\mathrm{hr}$, reverse.

used were as follows: $50^{\circ} \mathrm{C}$ for $3 \mathrm{~min}, 95^{\circ} \mathrm{C}$ for $3 \mathrm{~min}, 40$ cycles of $95^{\circ} \mathrm{C}$ for $10 \mathrm{sec}$ and $60^{\circ} \mathrm{C}$ for $30 \mathrm{sec}$. Relative quantification and calculations were performed using the comparative threshold (Cq) cycle method $\left(2^{-\Delta \Delta \mathrm{Cq}}\right)(16)$.

Statistical analysis. SPSS statistical analysis software (version 12.0; SPSS Inc., Chicago, IL, USA) was used to perform statistical analysis. Data are expressed as the mean \pm standard error and were analyzed by one-way analysis of variance followed by least significance difference test. $\mathrm{P}<0.05$ was considered to indicate a statistically significant difference.

\section{Results}

Effect of celecoxib on the viability of NCI-N87 cells. MTT analysis was performed to observe the effect of celecoxib treatment on NCI-N87 cell viability. The results demonstrated that cell viability was significantly inhibited in the celecoxib treatment group compared with the untreated cells $(\mathrm{P}<0.05$; Fig. 1A). To further understand the nature of the decrease in cell viability associated with the addition of celecoxib, cell cycle analysis was performed. The results suggested that compared with the control, there was an increased percentage of cells in the $\mathrm{G}_{0} / \mathrm{G}_{1}$ phase $(\mathrm{P}<0.05)$ and a decreased percentage of cells in the $\mathrm{S}$ and $\mathrm{G}_{2}$ phase in the celecoxib $(15 \mu \mathrm{M})$ treatment group $(\mathrm{P}<0.05$; Fig. 1B, Table II).

Effect of celecoxib on apoptosis in NCI-N87 cells. The apoptotic rate was analyzed by flow cytometry, and the results indicated that the percentage of early and late apoptotic cells was significantly increased in cells treated with celecoxib $(15 \mu \mathrm{M})$ compared with untreated cells $(\mathrm{P}<0.05 ;$ Fig. 2$)$. 

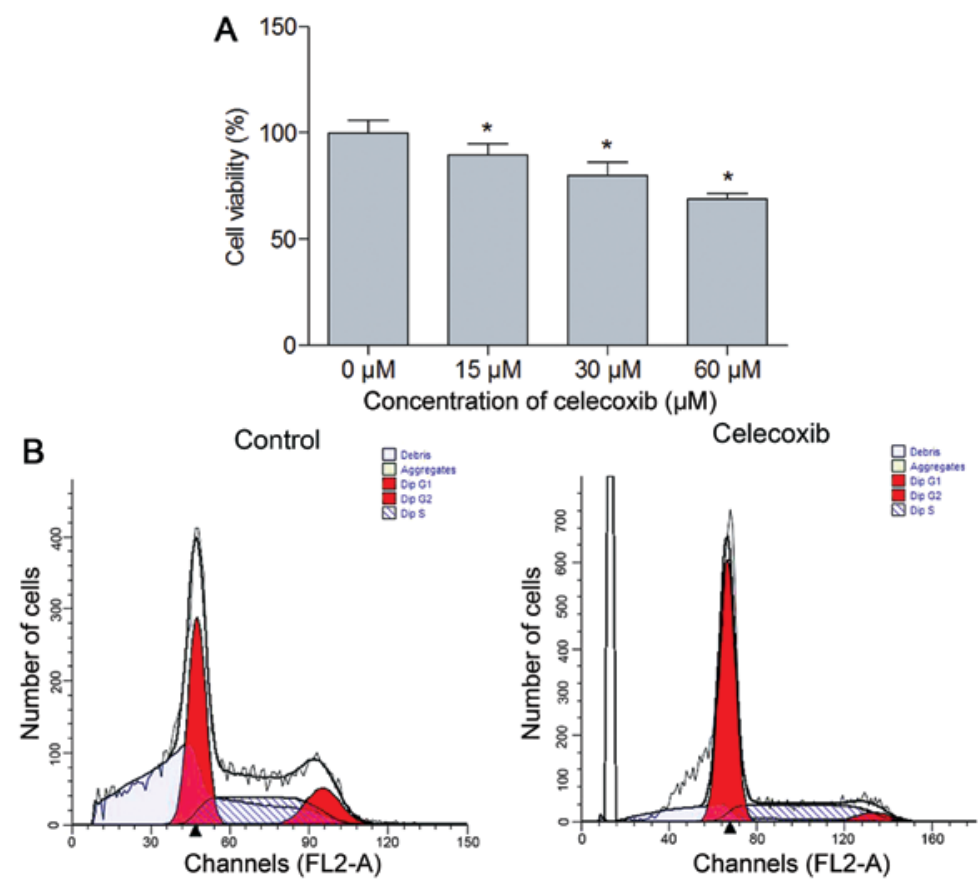

Figure 1. Celecoxib inhibits NCI-N87 cell viability. (A) MTT analysis demonstrated that cell viability was significantly inhibited in the celecoxib treatment group compared with untreated cells. (B) Flow cytometry analysis indicated an increase in the percentage of cells in the $\mathrm{G}_{0} / \mathrm{G}_{1}$ phase and a decrease in the percentage of cells in the $\mathrm{S}$ and $\mathrm{G}_{2}$ phases in the celecoxib treatment group compared with the control. " $\mathrm{P}<0.05$ vs. untreated cells. Dip, diploid.
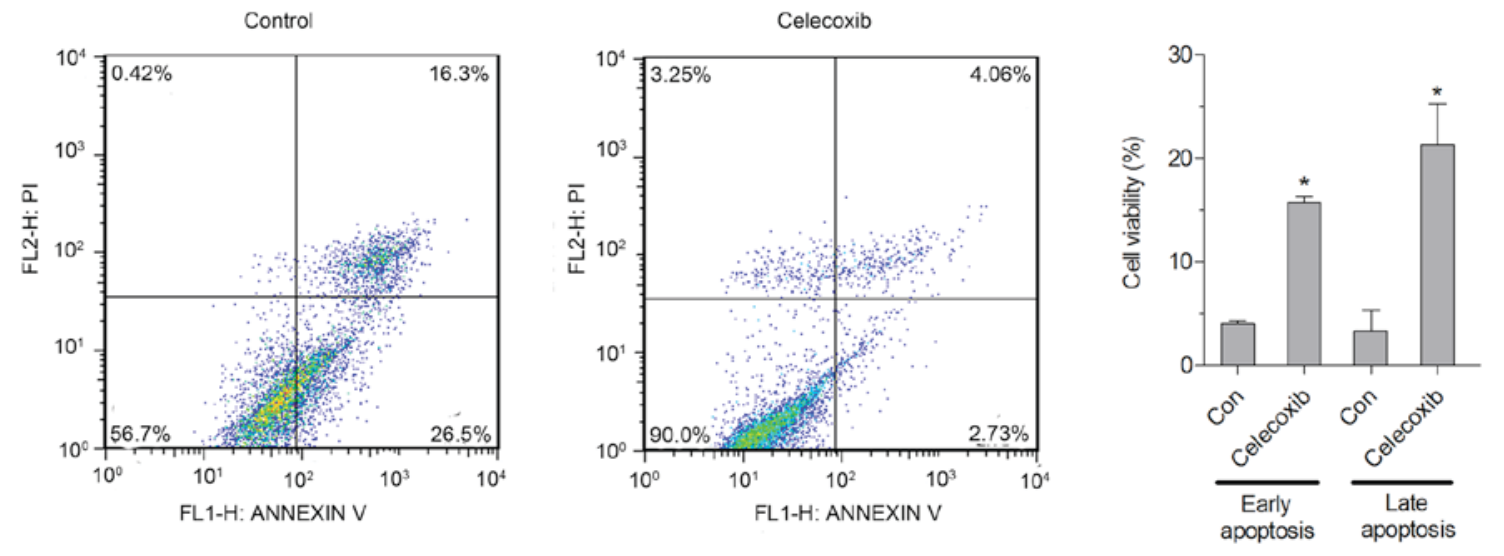

Figure 2. Celecoxib $(15 \mu \mathrm{M})$ promotes early and late apoptosis in NCI-N87 cells. "P<0.05 vs. control. Con, control. PI, propidium iodide.

Table II. Cell cycle analysis of celecoxib treatment and control groups.

\begin{tabular}{lccc}
\hline Group & $\begin{array}{c}\mathrm{G}_{0} / \mathrm{G}_{1} \\
\text { phase }(\%)\end{array}$ & $\begin{array}{c}\mathrm{S} \\
\text { phase (\%) }\end{array}$ & $\begin{array}{c}\mathrm{G}_{2} \\
\text { phase (\%) }\end{array}$ \\
\hline Control & $47.07 \pm 0.70$ & $39.05 \pm 4.34$ & $13.88 \pm 3.65$ \\
Celecoxib & $65.56 \pm 0.16^{\mathrm{a}}$ & $29.19 \pm 0.98^{\mathrm{a}}$ & $5.25 \pm 1.16^{\mathrm{a}}$ \\
\hline
\end{tabular}

${ }^{\mathrm{a}} \mathrm{P}<0.05$ vs. control. Data are expressed as the mean \pm standard error.

Effect of a low dose of celecoxib on the mRNA levels of lnc-SCD-1:13, lnc-PTMS-1:3, COX2, ITGA3 and DVL1 in NCI-N87 cells. There was no significant difference in the expression of $C O X 2$ in cells treated with celecoxib
$(15 \mu \mathrm{M})$ and untreated cells (Fig. 3). The mRNA levels of lnc-SCD-1:13, lnc-PTMS-1:3, ITGA3 and DVL1 were also detected. The expression of these genes was indicated to be aberrant in GC by our previous bioinformatics analysis (17). RT-qPCR analysis demonstrated that there was an increase in mRNA expression of $\operatorname{lnc}$-SCD-1:13, lnc-PTMS-1:3 ITGA3 and $D V L 1$ in cells treated with celecoxib $(15 \mu \mathrm{M})$ compared with untreated cells $(\mathrm{P}<0.05$, Fig. 3). Expression of $C O X 2$ was not significantly altered in cells treated with celecoxib $(15 \mu \mathrm{M})$ compared with untreated cells (Fig. 3).

\section{Discussion}

Celecoxib, a novel NSAID that is able to inhibit COX-2 activity, is considered to be an agent for the chemoprevention of GC (18). A previous study demonstrated that increased COX-2 expression is an independent prognostic factor for 

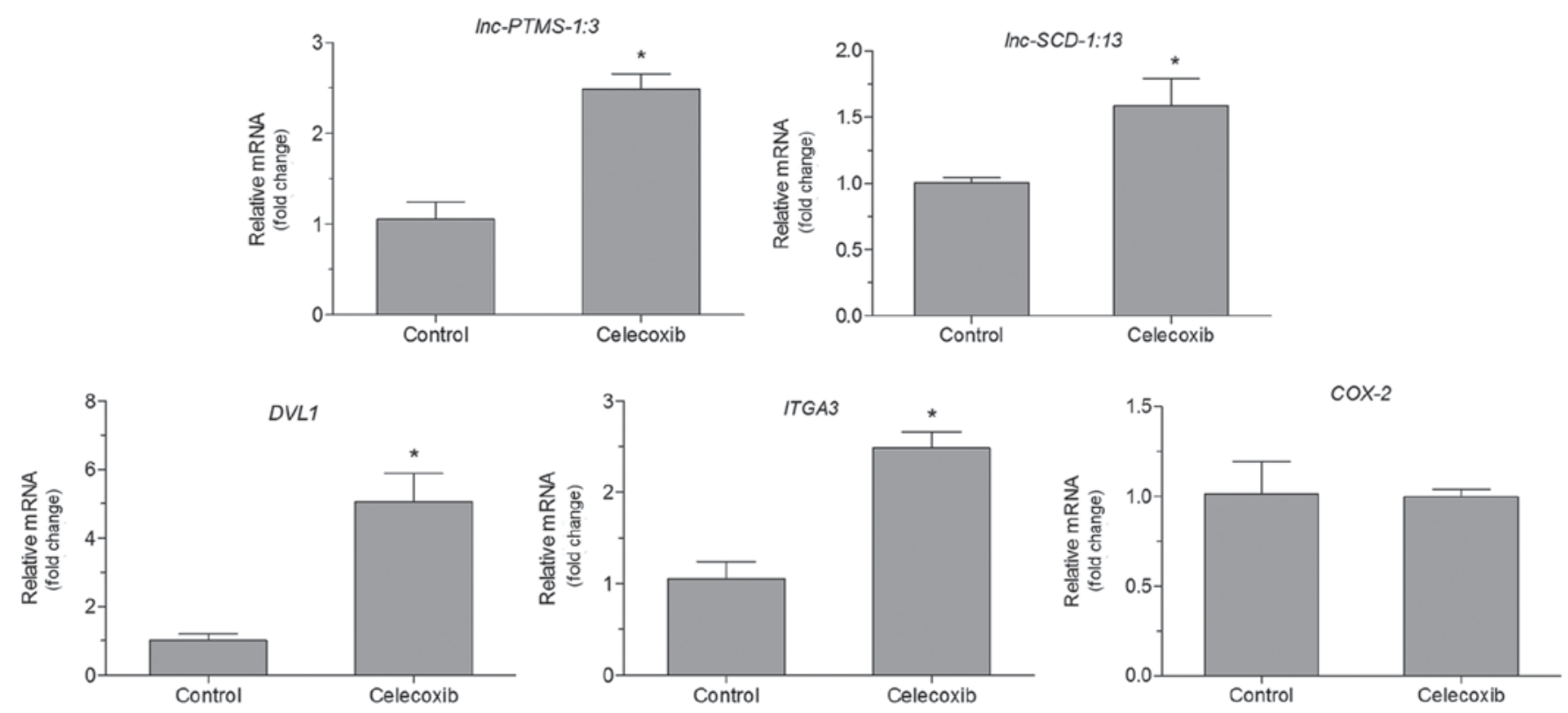

Figure 3. Celecoxib $(15 \mu \mathrm{M})$ increases mRNA expression of $\operatorname{lnc}-S C D-1: 13$, Inc-PTMS-1:3, ITGA3 and DVL1, but not COX-2 in NCI-N87 cells. "P $<0.05$ vs. control. lnc, long non-coding RNA; ITGA3, integrin subunit $\alpha 3$; DVL1, dishevelled segment polarity protein 1; COX-2, cyclooxygenase-2.

poor prognosis and is associated with reduced survival in patients with GC (19). Therefore, increasing attention had been directed to the mechanisms of celecoxib action on GC. In the present study, it was demonstrated that a low dose of celecoxib $(15 \mu \mathrm{M})$ was able to significantly inhibit viability of NCI-N87 cells by arresting the cell cycle at the the $G_{0} / G_{1}$ phase and promoting apoptosis. Similarly, Cho et al (20) demonstrated the anti-cancer effect of celecoxib on GC cells (AGS and MKN-45) by regulating cell-cycle arrest and apoptosis. In addition, Liu et al (11) suggested that celecoxib induced apoptosis through the mitochondrial and death receptor pathways in GC cells. These results indicated that a low dose of celecoxib may have a chemopreventive function in the development of $\mathrm{GC}$ by regulating cell cycle and apoptosis.

The association of COX2 with tumor development by promoting cell proliferation and invasion or metastasis has been well established (21,22). Previous studies have demonstrated that COX-2 is overexpressed in human GC $(23,24)$, and in vitro downregulation of COX-2 is able to induce growth inhibition (25). However, the present study indicated that $15 \mu \mathrm{M}$ celecoxib was not able inhibit $C O X 2$ mRNA expression, but was able to suppress cell viability. Consistent with the findings of the present study, Kim et al (26) also demonstrated that COX2 expression is not inhibited by $10 \mu \mathrm{M}$ celecoxib, but expression is suppressed by $25 \mu \mathrm{M}$ celecoxib. Taken together, these results indicated that the anti-cancer effect of celecoxib may not be fully dependent on COX-2 suppression. Previous studies have also demonstrated that chemopreventive effect of celecoxib on cancer may be associated with a COX-2-independent mechanism (13,27-29). Combined with the results of the present study, it is possible to hypothesize that a low dose of celecoxib may inhibit cell growth independent of COX-2. However, the exact mechanism requires further elucidation.

To further investigate the molecular mechanisms underlying the inhibition of cell viability induced by a low dose of celecoxib, the mRNA levels of differentially expressed genes (ITGA3 and
DVL1) and lncRNAs (lnc-SCD-1:13 and lnc-PTMS-1:3) were detected in NCI-N87 cells. ITGA3 has been previously been demonstrated to be involved in the development of GC (30). Integrins, a family of adhesion receptors, are associated with cell adhesion and migration as well as signal transduction $(31,32)$. Several previous studies have also demonstrated that decreased expression of ITGA3 is associated with cancer growth and development $(33,34)$. In addition, overexpression of DVL1 was observed in the metastasis of colorectal cancer (35). Dishevelled homologs (DVL1, DVL2, DVL2) are core signaling molecules of the WNT/planar cell polarity (PCP) signaling pathways (36). Accumulating evidence has demonstrated that PCP signaling is associated with tumorigenesis (31). Tang et al (37) reported that microRNA (miR)-200b and miR-22 were able to synergistically inhibit the growth of GC through the Wnt-1 signaling pathway. Notably, a previous study by our group demonstrated that ITGA3 and/or DVL1 were co-expressed with lnc-SCD-1:13 and lnc-PTMS-1:3 in GC cells. Further studies have reported that lncRNAs are involved in the pathogenesis of GC (38-40). These results suggested that genes co-expressed with lnc-SCD-1:13 and lnc-PTMS-1:3 may be involved in the effects of a low dose of celecoxib on GC. However, the associations of ITGA3 and DVL1 with 1nc-SCD-1:13 and lnc-PTMS-1:3 remain unclear, and should be investigated in further studies.

In summary, the present study demonstrated that a low dose of celecoxib may exert an anti-cancer effect by regulating the cell cycle and apoptosis independent of COX-2 in GC cells. Furthermore, ITGA3 and/or DVL1 co-expressed with lnc-SCD-1:13 and lnc-PTMS-1:3 may be involved in the effects of a low dose of celecoxib on GC.

\section{Acknowledgements}

The present study was supported by the Special Fund for Medical Service of Jilin Finance Department project (grant no. SCZSY201507). 


\section{References}

1. Bray F, Ren JS, Masuyer E and Ferlay J: Global estimates of cancer prevalence for 27 sites in the adult population in 2008. Int J Cancer 132: 1133-1145, 2013.

2. Ferlay J, Shin HR, Bray F, Forman D, Mathers C and Parkin DM: Estimates of worldwide burden of cancer in 2008: GLOBOCAN 2008. Int J Cancer 127: 2893-2917, 2010.

3. Akagi H, Higuchi H, Sumimoto H, Igarashi T, Kabashima A, Mizuguchi H, Izumiya M, Sakai G, Adachi M, Funakoshi S, et al: Suppression of myeloid cell leukemia-1 (Mcl-1) enhances chemotherapy-associated apoptosis in gastric cancer cells. Gastric Cancer 16: 100-110, 2013.

4. Harris RE, Namboodiri KK and Farrar WB: Nonsteroidal antiinflammatory drugs and breast cancer. Epidemiology 7: 203-205, 1996.

5. Funkhouser EM and Sharp GB: Aspirin and reduced risk of esophageal carcinoma. Cancer 76: 1116-1119, 1995.

6. Levy GN: Prostaglandin H synthases, nonsteroidal anti-inflammatory drugs and colon cancer. FASEB J 11: 234-247, 1997.

7. Hsu AL, Ching TT, Wang DS, Song X, Rangnekar VM and Chen CS: The cyclooxygenase-2 inhibitor celecoxib induces apoptosis by blocking Akt activation in human prostate cancer cells independently of Bcl-2. J Biol Chem 275: 11397-11403, 2000.

8. Wang WH, Huang JQ, Zheng GF, Lam SK, Karlberg J and Wong BC: Non-steroidal anti-inflammatory drug use and the risk of gastric cancer: A systematic review and meta-analysis. J Natl Cancer Inst 95: 1784-1791, 2003.

9. Pairet $\mathrm{M}$ and Engelhardt G: Distinct isoforms (COX-1 and COX-2) of cyclooxygenase: Possible physiological and therapeutic implications. Fundam Clin Pharmacol 10: 1-17, 1996.

10. Williams CS, Mann M and Dubois RN: The role of cyclooxygenases in inflammation, cancer, and development. Oncogene 18 : 7908-7916, 1999

11. Liu M, Li CM, Chen ZF, Ji R, Guo QH, Li Q, Zhang HL and Zhou YN: Celecoxib regulates apoptosis and autophagy via the PI3K/Akt signaling pathways in SGC-7901 gastric cancer cells Int J Mol Med 33: 1451-1458, 2014.

12. Lan C, Yang L, Fan L, Zhang Y, Wang J, Guo GJ, Wan S, Yang S, Wang R and Fang D: Celecoxib inhibits helicobacter pylori-induced invasion of gastric cancer cells through an adenine nucleotide translocator-dependent mechanism. Anticancer Agents Med Chem 13: 1267-1272, 2013.

13. Hu P, Yu J, Zeng Z, Leung WK, Lin HL, Tang BD, Bai AH and Sung JJ: Chemoprevention of gastric cancer by celecoxib in rats. Gut 53: 195-200, 2004

14. Du Z, Fei T, Verhaak RG, Su Z, Zhang Y, Brown M, Chen Y and Liu XS: Integrative genomic analyses reveal clinically relevant long noncoding RNAs in human cancer. Nat Struct Mol Biol 20: 908-913, 2013

15. Passon DM, Lee M, Rackham O, Stanley WA, Sadowska A, Filipovska A, Fox AH and Bond CS: Structure of the heterodimer of human NONO and paraspeckle protein component 1 and analysis of its role in subnuclear body formation. Proc Natl Acad Sci USA 109: 4846-4850, 2012.

16. Livak KJ and Schmittgen TD: Analysis of relative gene expression data using real-time quantitative PCR and the 2(-Delta Delta C(T)) method. Methods 25: 402-408, 2001.

17. Song B, Du J, Feng Y, Gao YJ and Zhao JS: Co-expressed differentially expressed genes and long non-coding RNAs involved in the celecoxib treatment of gastric cancer: An RNA sequencing analysis. Exp Ther Med 12: 2455-2468, 2016.

18. Yeh TS, Wu CW, Hsu KW, Liao WJ, Yang MC, Li AF, Wang AM, Kuo ML and Chi CW: The activated Notch1 signal pathways is associated with gastric cancer progression through cyclooxygenase-2. Cancer Res 69: 5039-5048, 2009.

19. Thiel A, Mrena J and Ristimäki A: Cyclooxygenase-2 and gastric cancer. Cancer Metastasis Rev 30: 387-395, 2011.

20. Cho SJ, Kim N, Kim JS, Jung HC and Song IS: The anti-cancer effect of COX-2 inhibitors on gastric cancer cells. Dig Dis Sci 52: $1713-1721,2007$.

21. Fu SL, Wu YL, Zhang YP, Qiao MM and Chen Y: Anti-cancer effects of COX-2 inhibitors and they correlation with angiogenesis and invasion in gastric cancer. World J Gastroenterol 10: 1971-1974, 2004
22. Greenhough A, Smartt HJ, Moore AE, Roberts HR, Williams AC, Paraskeva C and Kaidi A: The COX-2/PGE2 pathways: Key roles in the hallmarks of cancer and adaptation to the tumour microenvironment. Carcinogenesis 30: 377-386, 2009.

23. Ristimäki A, Honkanen N, Jänkälä H, Sipponen $P$ and Härkönen M: Expressions of cyclooxygenase-2 in human gastric carcinoma. Cancer Res 57: 1276-1280, 1997.

24. Uefuji K, Ichikura T and Mochizuki H: Cyclooxygenase-2 expressions is relate to prostaglandin biosynthesis and angiogenesis in human gastric cancer. Clin Cancer Res 6: 135-138, 2000.

25. Tsuji S, Kawano S, Sawaoka H, Takei Y, Kobayashi I, Nagano K, Fusamoto $\mathrm{H}$ and Kamada T: Evidences for involvement of cyclooxygenase-2 in proliferation of two gastrointestinal cancer cell lines. Prostaglandins Leukot Essent Fatty Acids 55: 179-183, 1996.

26. Kim N, Kim CH, Ahn DW, Lee KS, Cho SJ, Park JH, Lee MK, Kim JS, Jung HC and Song IS: Anti-gastric cancer effects of celecoxib, a selective COX-2 inhibitor, through inhibition of Akt signaling. J Gastroenterol Hepatol 24: 480-487, 2009.

27. Charalambous D and O'brien PE: Inhibition of colon cancer precursors in the rat by sulindac sulphone is not dependent on inhibition of prostaglandin synthesis. J Gastroenterol Hepatol 11: 307-310, 1996

28. Elder D, Halton DE, Hague A and Paraskeva C: Induction of apoptotic cell death in human colorectal carcinoma cell lines by a cyclooxygenase-2 (COX-2)-selective nonsteroidal anti-inflammatory drug: Independence from COX-2 protein expressions. Clin Cancer Res 3: 1679-1683, 1997.

29. Hanif R, Pittas A, Feng Y, Koutsos MI, Qiao L, Staiano-Coico L, Shiff SI and Rigas B: Effects of nonsteroidal anti-inflammatory drugs on proliferation and on induction of apoptosis in colon cancer cells by a prostaglandin-independent pathways. Biochem Pharmacol 52: 237-245, 1996

30. Song X, Zhong H, Zhou J, Hu X, Zhou Y, Ye Y, Lu X, Wang J, Ying B and Wang L: Association between polymorphisms of microRNA-binding sites in integrin genes and gastric cancer in Chinese Han population. Tumor Biol 36: 2785-2792, 2015.

31. Wang Y: Wnt/Planar cell polarity signaling: A new paradigm for cancer therapy. Mol Cancer Ther 8: 2103-2109, 2009.

32. Hemler ME: Integrin associated proteins. Curr Opin Cell Biol 10: $578-585,1998$.

33. Dedhar S, Saulnier R, Nagle R and Overall CM: Specific alterations in the expressions of $\alpha 3 \beta 1$ and $\alpha 6 \beta 4$ integrins in highly invasive and metastatic variants of human prostate carcinoma cells selected by in vitro invasion through reconstituted basement membrane. Clin Exper Met 11: 391-400, 1993.

34. Sampson-Johannes A, Wang W and Shtivelman E: Colonization of human lung grafts in SCID-hu mice by human colon carcinoma cells. Int J Cancer 65: 864-869, 1996.

35. Huang MY, Yen LC, Liu HC, Liu PP, Chung FY, Wang TN, Wang JY and Lin SR: Significant overexpression of DVL1 in taiwanese colorectal cancer patients with liver metastasis. Int J Mol Sci 14: 20492-20507, 2013.

36. Katoh M: WNT/PCP signaling pathways and human cancer (review). Oncol Rep 14: 1583-1588, 2005

37. Tang H, Kong Y, Guo J, Tang Y, Xie X, Yang L, Su Q and Xie X: Diallyl disulfide suppresses proliferation and induces apoptosis in human gastric cancer through Wnt-1 signaling pathways by up-regulation of miR-200b and miR-22. Cancer Lett 340: 72-81, 2013.

38. Lin XC, Zhu Y, Chen WB, Lin LW, Chen DH, Huang JR, Pan K, Lin Y, Wu BT, Dai Y and Tu ZG: Integrated analysis of long non-coding RNAs and mRNA expressions profiles reveals the potential role of lncRNAs in gastric cancer pathogenesis. Int J Oncol 45: 619-628, 2014.

39. Chen S, Li P, Xiao B and Guo J: Long noncoding RNA HMlincRNA717 and AC130710 have been officially name as gastric cancer associated transcript 2 (GACAT2) and GACAT3, respectively. Tumor Biol 35: 8351-8352, 2014.

40. Okugawa Y, Toiyama Y, Hur K, Toden S, Saigusa S, Tanaka K, Inoue Y, Mohri Y, Kusunoki M, Boland CR and Goel A: The expressions of metastasis-associated long non-coding RNA, HOTAIR, is involved in cancer development and peritoneal metastasis in gastric cancer. Cancer Res 74: 3553-3553, 2014. 